\title{
Placebo effects in children: a review
}

\author{
Katja Weimer' ${ }^{1}$, Marco D. Gulewitsch², Angelika A. Schlarb², Juliane Schwille-Kiuntke', Sibylle Klosterhalfen and Paul Enck ${ }^{1}$
}

Of more than 155,000 PubMed citations found with the search term "placebo," only 9,000 (5.8\%) included the terms "children" or "adolescents." When all these papers were screened, only $\sim 2,000$ of them investigated the placebo effect per se, and of those, only 50 (2.5\%) discussed the placebo effect in children and adolescents. In this narrative review, we explore four aspects of the placebo response in children and adolescents: (i) the legal and ethical limitations and restrictions for the inclusion of children in clinical trials as well as in experimental (placebo) research that may explain the poor knowledge base; (ii) the question of whether or not the placebo effect is larger in children and adolescents as compared with adults; (iii) whether the mechanisms underlying the placebo effect are similar between children and adults; and (iv) whether mediators and moderators of the placebo effect are comparable between children and adults. We finally discuss some of the consequences from the current placebo research in adults that may affect both experimental and clinical research in children and adolescents.

ittle is known about placebo effects in children, and the -majority of this knowledge derives from review articles and reanalyses and meta-analyses of clinical trials over the past $20 \mathrm{y}$, especially in the areas of attention-deficit hyperactivity disorder (ADHD), depression, and migraine. To our knowledge, only a few experimental studies exist that investigated the placebo effect and its mechanisms per se in children and adolescents. Furthermore, there is little knowledge about placebo effects in children younger than $6 \mathrm{y}$.

Of more than 155,000 PubMed citations with the term "placebo," only 9,000 (5.8\%) included the search terms "children" or "adolescents." When all these papers were screened, only $\sim 2,000$ discussed the placebo effects per se (1), and of those, only $\sim 50(2.5 \%)$ investigated the placebo response in children and adolescents.

Placebo research has gained momentum in recent years with respect to its underlying neurophysiological and psychobiological mechanisms (2) as well as with respect to its clinical relevance in drug trials and clinical routine (3). However, a number of issues have remained unsolved, among which are the effects of age (4), gender differences (5), and the contribution of genetic and psychological profiles. It still is an unsolved puzzle whether placebo responders may be reliably distinguished from placebo nonresponders (6), and this applies not only to the adult population but also to children and adolescents.

In this narrative review, we discuss four aspects of the placebo response in children and adolescents: (i) The legal and ethical limitations and restrictions for the inclusion of children in clinical and experimental trials that may explain the currently poor knowledge base; (ii) the question of whether or not the placebo response is larger in children and adolescents as compared with adults; (iii) whether the mechanisms of the placebo response allow a comparison of children and adults; and (iv) whether mediators and moderators of the placebo response are similar or different between children and adults. We finally discuss some of the consequences from the current placebo research in adults, which may affect both experimental and clinical research in children and adolescents, and future research possibilities.

\section{LEGAL AND ETHICAL CONSIDERATIONS FOR THE} INCLUSION OF CHILDREN IN CLINICAL TRIALS

Current legal and ethical rules for the inclusion of children into randomized, double-blinded, and placebo-controlled trials are far from being clear and are to some degree even contradictory.

Guidelines of the US National Institutes of Health (7), the US Food and Drug Administration (8), and the European Medicines Agency (9) explicitly call for the need to include children into the testing of novel compounds as long as no specific reasons argue against it $(10,11)$, as drugs should not be used in children without such tests and their use should not merely be based on dose adjustments from doses for adults, e.g., based on body weight.

In contrast to the policy of drug approval authorities, the Declaration of Helsinki of the World Medical Association in its current version (as of 2008) (12) does not explicitly mention children but includes them among all "incompetent" persons who are not to be included in placebo-controlled trials unless important reasons argue in favor of such inclusion, e.g., no adequate medication is available that is approved for use in adults (13).

Common to both sets of rules is that children can only be included in trials after careful consideration of the risks and benefits (14).

Further ethical principles are the protection of "integrity, right to self-determination, privacy, and confidentiality of personal information of research subjects" (p. 2) (12). In adult or competent persons, these requirements are fulfilled by the 


\section{Placebo effects in children}

process of informed consent that particularly includes adequate information about the study aims and methods, storage of personal information, voluntariness of participation, and the right to refuse participation at any time. For incompetent persons, this informed consent must be given by a legally authorized representative, but if they are able to agree, their decision must be taken into consideration (12). For the inclusion of children, these requirements imply specific burden: physicians and parents have to decide at which age or cognitive developmental stage children are able to agree or disagree to study participation, and information must be designed in a written or verbal way they are able to understand. For example, in the case of randomized placebo-controlled trials, children have to understand that they could be assigned to take pills without any active medication.

According to the Declaration, not only children but also adults are only to be exposed to placebo treatment in case other adequate treatment options are not available (12). By contrast, the World Medical Association Declaration of Helsinki favors the position that novel compounds can only be tested against the best medical therapy currently available (comparative effectiveness research), and thus calls for more "comparator trials" in which new drugs are tested for their noninferiority in comparison with other and available treatment options (15). However, as has been shown (16), the likelihood of receiving active treatment may determine the size of the placebo response, with higher placebo response rates when the chances of active treatment increase above $50 \%$. Whether this is also the case in children is unknown and needs to be determined.

In this respect, comparator trials (or comparative effectiveness research) induce a $100 \%$ chance for active treatment and thereby generate a substantially and significantly higher placebo response and a poorer discrimination between drug and placebo than do placebo-controlled trials (17), thus creating an interesting ethical dilemma (18): Although they attempt to minimize the number of patients who are withheld from being adequately treated, they in fact require more patients to be included in the trial for statistical testing of drug efficacy (noninferiority). This would create specific burden to studies in children and adolescents if-as we will discuss below-their placebo response rate would differ from that of adults.

\section{ARE PLACEBO RESPONSES DIFFERENT BETWEEN CHILDREN AND ADULTS?}

Reviews and meta-analyses usually conclude that the placebo response rates in trials in general are higher in children and adolescents than in adults but that the drug responses are equal among them (see below). In consequence of this, drug effects cannot be calculated in children on the basis of data generated with adults, as stated above. This also implies that more children have to be included in drug trials to achieve the same degree of security of drug efficacy as in adults. However, only very few reviews and meta-analyses directly compared placebo effects in children, adolescents, and adults, and only indirect comparisons of separate studies in these populations are possible for most conditions.
In a meta-analysis of randomized and placebo-controlled treatment trials in pediatric major depression, Bridge et al. (19) found that-with the exception of one treatment trial with a selective serotonin reuptake inhibitor (20)-the placebo response was significantly higher in children younger than 12 years $(54.3 \%)$ as compared with children older than 12 years (44.9\%), whereas the drug response was similar (58.4 and $61.5 \%$, respectively). By contrast, meta-analytic data from studies in adults using similar drugs and end points revealed an average placebo response rate of $34.7 \%$ (17).

A similar result was found by Rheims et al. (21) with respect to treatment studies for epilepsy: children had a significantly higher placebo response rate in comparison with adults (19.0 vs. $9.9 \%$ ), whereas the efficacy of the medication was not statistically different between the two groups (37.2 vs. $30.4 \%$ ).

A systematic review on oral triptanes in the treatment of acute migraine headache revealed that the only two studies between 1991 and 2002 that reported results in children and adolescents showed on average a significantly higher response rate $(48.5 \%)$ and number of pain-free patients $(25.5 \%) 2 \mathrm{~h}$ after placebo intake in comparison with adults (28.9 and 6.1\%, respectively) (22).

A review of drug treatment in ADHD in children reported mean placebo response rates of $20-30 \%$ in children (23), and a comparable review in adults noted a $10 \%$ response with placebo (24). The guidelines for ADHD treatment in adults list studies with a placebo response ranging between 0 and 17\% (25).

In an editorial for a study by Saps et al. (26), Benninga and Mayer (27) quoted lower placebo response rates in adults with pain-related functional gastrointestinal disorders. Saps et al. (26) detected no difference in the effectiveness of amitriptyline, a tricyclic antidepressant, (63.0\%) and placebo (57.5\%) in the treatment of pediatric pain-related functional gastrointestinal disorders and pointed toward the fact that in comparable studies among adults, placebo response rates were substantially lower and in the range of $40 \%$ across many trials (28).

In a systematic review of placebo response rates in children with psychiatric conditions (major depression disorder, obsessive-compulsive disorder, and nonobsessive-compulsive disorder anxiety disorders), Cohen et al. (29) noted higher placebo response rates in children than in adolescents, although these differences were not statistically significant. Furthermore, these and the pooled response rates are higher than those known for adults with similar conditions (Table 1).

Table 1. Placebo response rates in children, adolescents, and adults with psychiatric disorders

\begin{tabular}{lcccc}
\hline & MDD (\%) & OCD (\%) & AD (\%) & References \\
\hline Children & 60 & 40 & 42 & 29 \\
Adolescents & 49 & 32 & 32 & 29 \\
Pooled & 50 & 31 & 40 & 29 \\
Adults & 38 & 23 & 33 & $17,82,83$ \\
\hline
\end{tabular}

"Pooled" refers to the pooling of data for children and adolescents in ref. 29.

$A D$, anxiety disorders without OCD; MDD, major depression disorder; $\mathrm{OCD}$, obsessive-compulsive disorder. 


\section{Review | weimere tal.}

Examples of psychiatric and nonpsychiatric trials are reviewed in a recent paper by Parellada et al. (30).

In addition, the frequent use of homeopathy in children (31) - beyond the question of whether homeopathy is placebo treatment per se (32) - and placebo response rates in food challenges (33) argue in favor of higher placebo responses in children as compared with adults.

By contrast, only one review-type article reports no age effects on the placebo response size in clinical studies in migraine headache (34).

Taken together, these reports strongly imply that age is negatively correlated with the size of the placebo response.

\section{ARE THE MECHANISMS UNDERLYING THE PLACEBO EFFECT SIMILAR BETWEEN CHILDREN AND ADULTS?}

It is assumed that the placebo response is mainly generated by two distinct mechanisms: expectancies on one hand and Pavlovian conditioning on the other (2,3). A similar assumption has been proposed for children and adolescents (35), but the possibility that further mechanisms, such as instrumental learning (36) or learning by imitation (37), exist cannot be excluded. Furthermore, the contribution of genetic factors is likely but has only been shown in a few studies with adults so far (38-40).

Beyond associative learning (Pavlovian conditioning and instrumental learning), children could probably be susceptible to learning by imitation and role models. In an experimental setup, Colloca and Benedetti (37) compared three groups of (adult) volunteers in a pain experiment in which painful cutaneous stimuli were announced following a red signal light, whereas a green light would indicate nonpainful stimuli; in all cases, the stimuli were equal in intensity. In one subgroup, subjects could observe another volunteer during performance before being tested; in a second group, they were exposed to a Pavlovian conditioning procedure; and in a third group, the cognitive expectancy of stimulus intensity was manipulated. Results showed conditioning and imitation learning to be equally effective (43.4 and $39.2 \%$ pain reduction) as compared with expectancy alone (8.4\%).

One could speculate that given higher learning capacities in children (aged $6 \mathrm{y}$ and older) as compared with adults, at least for associative learning, children would exhibit higher placebo responses in clinical trials. Surprisingly, direct comparison of the effect size of associative learning, e.g., with anticipatory nausea during chemotherapy, has never been performed, despite the fact that both children and adults have been shown to be affected (41) and to be responsive to behavioral countermeasures based on such learning, e.g., latent inhibition and overshadowing (42).

Similar assumed mechanisms generate the question of why placebo effects should be higher in children as compared with adults. Among the offered explanations are not only higher expectations of parents and their respective behaviors $(23,27)$ but also the increased attention of the media (43). This mayvia increased parents' attention-lead to higher expectations of children, and parents may direct their attention toward symptom improvement (23). It is speculative but likely that the "regression to the mean" effect may be larger in studies of children because parents may exaggerate their children's symptoms at the time of recruitment to make sure their children are included (21). In contrast to adults, children tend to assume more often to be included in the medication arm rather than in the placebo arm of the study (44) and apparent unblinding of studies due to parents' observation of their children's behavior appears to be frequent (45).

A recent meta-analysis of 31 depression trials in children and adolescents (46) contradicts some of these assumptions. They found that despite higher placebo response rates in children, they cannot be attributed to most of the factors that have been found responsible for high placebo response rates in adults, e.g., the amount of contact with medical staff or the chances of receiving active treatment. In placebo-controlled trials, however, placebo responses significantly increase with the amount of therapeutic contact in adolescent but not in younger patients. The authors conclude that whereas patient expectancy strongly influences response rates to medication and placebo in depressed adults, it appears to be less important in the treatment of children with depression. Attempts to limit placebo response and improve the efficiency of antidepressant trials for pediatric depression should focus on other causes of placebo response apart from expectancy (46). This seems traceable because younger children may not deal with abstract expressions such as "probability" or "placebo."

By contrast, a meta-analysis by Evers et al. (34) identified 8 crossover and 11 parallel-group trials on acute treatment of migraine headache in which the placebo response rates were considerably lower in crossover trials than in parallel-group trials ( 19.2 vs. $27.1 \%$ for the end point "pain free" after $2 \mathrm{~h}$ and 39.4 vs. $56.9 \%$ for "pain relief" after $2 \mathrm{~h}$ ). Whereas crossover trials provide a $100 \%$ chance for every patient to receive placebo treatment, in parallel-group trials, the chance to receive inactive treatment depends on the number of study groups but is not higher than $50 \%$ when there is at least one active medication group. Therefore, the results are comparable with findings from an older meta-analysis of migraine treatments in adults by Diener et al. (47) that reported increasing placebo response rates with increasing likelihood of receiving active treatment. Taken together, these results could indirectly imply an awareness of expressions such as "probability" and "placebo" in studies with children too, although it cannot be excluded that it depends more on reactions of parents as stated above. However, crossover trials-although they also provide a $100 \%$ chance of receiving active treatment-have another pitfall that may corrupt proper estimation of drug and placebo effects: patients who receive the drug first and then the placebo may show higher placebo response rates (due to conditioned drug effects from the first treatment phase) (48) than those who receive the placebo first and then the drug - the latter may "profit" from the natural course of disease that frequently occurs in acute medical conditions (49) but is incorrectly attributed to the drug effect. 


\section{Placebo effects in children $\mid$ Review}

ARE THE MEDIATORS AND MODERATORS OF THE PLACEBO EFFECT SIMILAR BETWEEN CHILDREN AND ADULTS?

Although age appears to be a relevant moderator of the placebo response (as discussed above), gender differences in adults were occasionally investigated, but results are generally not consistent $(5,50,51)$. However, experimental studies on placebo analgesia usually reveal higher placebo response rates in male adults (52). To our knowledge, there are only two articles that report analyses of gender differences in the placebo response in children: the review by Evers et al. (34) found no gender differences, whereas the other review (53), also focusing on migraine headache, found higher placebo response rates in girls (66.7\%) as compared with boys (43.3\%).

Among the many personality characteristics that have been tested for predicting placebo response in clinical and experimental trials, only a few have gained more than incidental importance, and many more may never have been reported due to missing predictive value. Hypnotic and other suggestibility (54), dispositional optimism (55), the locus of control (56), negative emotions such as fear and anxiety (57), and other psychometric characteristics have never been tested with respect to placebo responses in children and adolescents. However, it is well established that personality, coping characteristics, and outcome expectancies (e.g., negative expectancies, low self-efficacy, and locus of control) codetermine health behavior (58) and outcome of interventions (59) in a rather complex manner in chronic conditions. It is thus likely that similar effects of these personality characteristics determine positive treatment outcomes also with "placebo" interventions in adults, adolescents, and children.

Other reviews that have attempted to identify differences between responders and nonresponders, such as the review by Newcorn et al. (60), reported higher placebo response rates in children with ADHD when they were easy to distract, had not had stimulating medication before, presented with comorbid tics, and were of non-Caucasian origin. Cohen et al. (61) identified a Caucasian origin, the duration of the disorder, its severity at onset, and the result of treatment as predictors of a nonresponse to placebo in psychotropic medication trials in major depression, anxiety, and compulsive behavior. In a reanalysis of data of the placebo arm of a lithium trial in aggressive children with behavioral problems, Sanchez et al. (62) found that placebo responders more often grew up in families with a high aggression potential, e.g., with parents having a criminal background, and lower placebo response rates were associated with milder ADHD symptoms.

These findings point toward another factor that would need exploration for placebo research in children: studies have shown that parents' beliefs and their stress levels largely affect physical and psychological functioning in children (63) and adolescents (64). The same moderators will likely operate in pediatric clinical trials and will determine the success and failure of medical interventions. If so, they may as well explain why moderators effective in the placebo response in adults, e.g., the amount of professional attention a patient receives (see above) are not operating or not operating as well in children
(46), and other moderators may be more effective that have not been identified in adults in respective meta-analyses.

It has been argued (65) that placebos could operate by producing changes in how caregivers perceive children's symptom changes. Placebos could also operate by producing changes in how caregivers behave toward children, which in turn produce behavioral changes in the child. This concept of "placebo by proxy" has recently received attention both from a methodological point of view (66) and in an observational study on temper tantrums in children (67).

Grelotti and Kaptchuk (66) argued that the expectations of a patient toward his/her treatment are not only based on his/ her own experience and hopes but also occur in a social context, in which proxies (family members, caregivers, and relatives) respond to symptoms and their improvement as well as their worsening. Because these can exist independently of any placebo response of the patient, their contribution to the patient's response are largely unknown and uninvestigated. One of the paradigmatic examples the authors cite refers to the fact that antibiotics are frequently overprescribed specifically in children because of parents' concerns and wishes (68). Proxies' influences on (placebo) responsiveness may also be responsible for differences in efficacy reports seen between doctor and patient-reported outcomes, especially in depression (69).

Whalley and Hyland (67) take the argument that placebo by proxy may play an important role especially in children one step further: they investigated whether the efficacy of an impure placebo (Bach flower therapy, a homeopathic remedy) to improve symptoms of temper tantrums in 2-5-y-old children would be affected by the parents' beliefs and moods. To exclude any direct effect of physician-child and physicianparent interaction, an automated telephone system was used for symptom recording. The authors found a sustained and significant improvement of tantrum frequency and severity that was strongly correlated to parents' mood. Because this was an observational study, the authors were not able to conclude the true nature of the symptomatic improvement but assumed that these are "pure" placebo effects. Whether symptom improvements were mirrored in children's behavioral changes or only in parents' perception cannot be concluded from the data.

\section{WHAT ARE THE CONSEQUENCES FOR CLINICAL AND EXPERIMENTAL STUDIES AND FUTURE RESEARCH?}

Evidently, if placebo response rates in clinical trials with children are higher than the response rates of adults with similar or other drugs/interventions in similar clinical conditions and across many diseases, then extrapolating drug efficacy in children from respective studies in adults runs the risk of underestimating the placebo response and overestimating drug efficacy. An apparent immediate consequence of this would be the need to conduct specific pediatric trials and to increase the number of pediatric patients in such randomized controlled trials (as compared with the number of patients in adult trials) to achieve "significance" of the data-this would create a similar ethical paradox as the one discussed above with comparative 
Table 2. Principle of conditioning of drug effects with partial reinforcement

\begin{tabular}{|c|c|c|c|c|c|c|c|c|c|c|c|c|c|c|c|c|c|c|c|c|c|c|c|c|c|c|}
\hline \multicolumn{14}{|c|}{ Acquisition period } & \multicolumn{13}{|c|}{ Maintenance treatment } \\
\hline \multicolumn{14}{|c|}{ Day of treatment } & \multicolumn{13}{|c|}{ Day of treatment } \\
\hline 1 & 2 & 3 & 4 & 5 & 6 & 7 & 8 & 9 & 10 & 11 & 12 & 13 & 14 & 15 & 16 & 17 & 18 & 19 & 20 & 21 & 22 & 23 & 24 & 25 & 26 & 27 \\
\hline
\end{tabular}

This example shows a drug application regime with a 2-wk acquisition period, followed by drug applications with interspersed placebos (likelihood of placebo application in week 3 and 4:0.50) (modified with permission from ref. 3).

D, drug; P, placebo.

effectiveness research trials (18) and hence is not feasible in pediatric trials. As stated above, inclusion of children and adolescents as incompetent but self-determined persons (12) requires specific considerations that influence study designs. Whether adapted study designs from adult patients may affect study outcomes in children and adolescents is unknown.

We have recently proposed (70) that minimizing the placebo response rate in randomized controlled trials is but one strategy to gain insight into drug efficacy on the one hand and into mechanisms behind the placebo response on the other. Factors that influence drug-placebo differences can be derived from studies that examine placebo response predictors, but an ideal study design has not yet been found. For example, drug-placebo differences can be best detected in studies with a $50 \%$ chance to receive drug or placebo (16), but as discussed above, there are ethical limitations for such study designs not only in adults but also specifically in children and adolescents.

By contrast, maximizing the placebo response (in comparison with a standard "treatment as usual" or a no-treatment control group) may be a better way to use the placebo mechanisms (70), especially in children and adolescents. Two recent examples of conditioning from the published literature may illustrate such a strategy: preconditioning drug effects during an initial run-in phase (Table 2) was shown to reduce subsequent drug dosing by up to $50 \%$ in an adult trial of corticosteroid therapy in psoriasis (71) and in medication therapy of children with ADHD (72). Another possibility to harness the placebo effect could be to optimize expectations of patients (73): In adults, verbal instructions may shape expectations that decrease (or increase) sensations of itch and pain (74) or reveal placebo analgesia by reducing anxiety (57) not only in healthy volunteers but also in patients with irritable bowel syndrome (75). One of the rare experimental studies in children and adolescents also revealed effects of verbal instructions on needle pain from venipuncture (76). Furthermore, warm empathic interactions between practitioners and patients have been shown to evoke significant placebo effects in adult patients with irritable bowel syndrome (50). Therefore, the effects of expectations and of patient-practitioner interactions on symptoms in children and adolescents, as well as their mediation by parents, should be further investigated.

Using placebo mechanisms in daily practice implies ethical considerations such as required informed consent (73). However, research groups have also demonstrated efficacy of an open-label placebo intervention in ADHD (77) similar to a trial in adult patients with irritable bowel syndrome (78).
In summary, more experimental research is needed for the assessment of placebo responses and mechanisms as well as for other and alternative study designs in children and adolescents. Future research could be based on results from experimental and clinical studies in adults, e.g., on effects of conditioning and expectations, but should take into account that mechanisms, moderators, and mediators in children and adolescents may be different from those of adults. Furthermore, reviews and meta-analyses on placebo effects in adults showed that the susceptibility to placebo mechanisms varies among symptoms, conditions, and diseases (3), but comparisons with children and adolescents are missing. Designs that have been proposed for adults (79) need to be explored for the younger ones as well. Among them, the recently proposed "free-choice paradigm" (80) may be specifically suitable for children, as it avoids many ethical concerns and favors simple and childadequate choice behavior rather than symptom improvement as an outcome measure. The example by Whalley and Hyland (67) illustrates that it will also be feasible to separate placebo effects of the patient from those of proxies.

\section{SUMMARY AND CONCLUSION}

The few available data on placebo response rates in children and adolescents as compared with adults allow only preliminary conclusions: response rates appear to be higher in children and adolescents than in adults, and the underlying mechanisms, such as expectancy and conditioning, appear to be the same in all the age groups. However, in light of the reported (46) lower efficacy of expectancy factors, such as the amount of physician contact time during trial, (Pavlovian) conditioning and other learning mechanisms may play a greater role in generating placebo responses in children as compared with adults. As has also been shown in adults, the balance between expectancy and learning mechanisms may vary substantially, e.g., between genders (81), and may account for apparently similar placebo response rates, despite the different mechanisms that have generated them. In addition, the role of placebo by proxy needs further exploration, and specific trial designs for children and adolescents need to be developed. It also needs to be shown whether learning and conditioning plays a greater role in the placebo response in children and adolescents as compared with adults.

\section{STATEMENT OF FINANCIAL SUPPORT}

This work was supported by a grant from Deutsche Forschungsgemeinschaft (grant En 50/30-1).

Disclosure: The authors declare no conflict of interest. 


\section{Placebo effects in children Review}

\section{REFERENCES}

1. Enck P, Klosterhalfen S. [Placebo response and placebo effect - mechanisms, mediators, moderators]. Psychother Psychosom Med Psychol 2012;62:229-41.

2. Enck P, Benedetti F, Schedlowski M. New insights into the placebo and nocebo responses. Neuron 2008;59:195-206.

3. Rief W, Bingel U, Schedlowski M, Enck P. Mechanisms involved in placebo and nocebo responses and implications for drug trials. Clin Pharmacol Ther 2011;90:722-6.

4. Kemeny ME, Rosenwasser LJ, Panettieri RA, Rose RM, Berg-Smith SM, Kline JN. Placebo response in asthma: a robust and objective phenomenon. J Allergy Clin Immunol 2007;119:1375-81.

5. Weimer K, Enck P, Klosterhalfen S. [Gender effects in placebo responses]. Z Med Psychol 2010;19:146-53.

6. Kaptchuk TJ, Kelley JM, Deykin A, et al. Do "placebo responders" exist? Contemp Clin Trials 2008;29:587-95.

7. Taylor-Zapata P. Pediatric Clinical Trials and The Best Pharmaceuticals for Children Act. Workshop on Ethical and Regulatory Issues in Global Pediatric Trials 2009, Eunice Kennedy Shriver National Institute of Child Health and Human Development, National Institutes of Health Office of Pediatric Therapeutics. Rockville, MD: US Food and Drug Administration, 20-22 September 2009.

8. Committee on Drugs, American Academy of Pediatrics. Guidelines for the ethical conduct of studies to evaluate drugs in pediatric populations. Pediatrics 1995;95:286-94.

9. Regulation (EC) No. 1901/2006 of the European Parliament and of the Council of 12 December 2006 on medicinal products for paediatric use and amending Regulation (EEC) No. 1768/92, Directive 2001/20/EC, Directive 2001/83/EC and Regulation (EC) No. 726/2004. Official Journal of the European Union, 27 December 2006, L378/1.

10. Miller FG, Wendler D, Wilfond B. When do the federal regulations allow placebo-controlled trials in children? J Pediatr 2003;142:102-7.

11. Derivan AT, Leventhal BL, March J, Wolraich M, Zito JM. The ethical use of placebo in clinical trials involving children. J Child Adolesc Psychopharmacol 2004;14:169-74.

12. Yan EG, Munir KM. Regulatory and ethical principles in research involving children and individuals with developmental disabilities. Ethics Behav 2004;14:31-49.

13. Roth-Cline M, Gerson J, Bright P, Lee CS, Nelson RM. Ethical considerations in conducting pediatric research. Handb Exp Pharmacol 2011;205:219-44.

14. Linde M, May A, Limmroth V, Dahlöf C; Headache Masters Programme. Ethical aspects of placebo in migraine research. Cephalalgia 2003;23: 491-5.

15. Johnson ES, Bartman BA, Briesacher BA, et al. The incident user design in comparative effectiveness research. Effective Health Care Program Research Report No. 32. (Prepared under Contract No. HHSA290200500161). AHRQ Publication No. 11(12) - EHC054-EF. Rockville, MD: Agency for Healthcare Research and Quality. May 2012. (http://effectivehealthcare.ahrq.gov/ reports/final.cfm) Accessed 27 May 2012.

16. Papakostas GI, Fava M. Does the probability of receiving placebo influence clinical trial outcome? A meta-regression of double-blind, randomized clinical trials in MDD. Eur Neuropsychopharmacol 2009;19:34-40.

17. Rutherford BR, Sneed JR, Roose SP. Does study design influence outcome? The effects of placebo control and treatment duration in antidepressant trials. Psychother Psychosom 2009;78:172-81.

18. Enck P, Klosterhalfen S, Weimer K, Horing B, Zipfel S. The placebo response in clinical trials: more questions than answers. Philos Trans R Soc Lond, B, Biol Sci 2011;366:1889-95.

19. Bridge JA, Birmaher B, Iyengar S, Barbe RP, Brent DA. Placebo response in randomized controlled trials of antidepressants for pediatric major depressive disorder. Am J Psychiatry 2009;166:42-9.

20. Emslie GJ, Rush AJ, Weinberg WA, et al. A double-blind, randomized, placebo-controlled trial of fluoxetine in children and adolescents with depression. Arch Gen Psychiatry 1997;54:1031-7.

21. Rheims S, Cucherat M, Arzimanoglou A, Ryvlin P. Greater response to placebo in children than in adults: a systematic review and meta-analysis in drug-resistant partial epilepsy. PLoS Med 2008;5:e166.
22. Loder E, Goldstein R, Biondi D. Placebo effects in oral triptan trials: the scientific and ethical rationale for continued use of placebo controls. Cephalalgia 2005;25:124-31.

23. Waschbusch DA, Pelham WE Jr, Waxmonsky J, Johnston C. Are there placebo effects in the medication treatment of children with attention-deficit hyperactivity disorder? J Dev Behav Pediatr 2009;30:158-68.

24. Wilens TE, Spencer TJ, Biederman J. A review of the pharmacotherapy of adults with attention-deficit/hyperactivity disorder. J Atten Disord 2002;5:189-202.

25. Ebert D, Krause J, Roth-Sackenheim C. [ADHD in adulthood-guidelines based on expert consensus with DGPPN support]. Nervenarzt 2003;74:939-46.

26. Saps M, Youssef N, Miranda A, et al. Multicenter, randomized, placebocontrolled trial of amitriptyline in children with functional gastrointestinal disorders. Gastroenterology 2009;137:1261-9.

27. Benninga MA, Mayer EA. The power of placebo in pediatric functional gastrointestinal disease. Gastroenterology 2009;137:1207-10.

28. Enck P, Horing B, Weimer K, Klosterhalfen S. Placebo responses and placebo effects in functional bowel disorders. Eur J Gastroenterol Hepatol 2012;24:1-8.

29. Cohen D, Deniau E, Maturana A, et al. Are child and adolescent responses to placebo higher in major depression than in anxiety disorders? A systematic review of placebo-controlled trials. PLoS ONE 2008;3:e2632.

30. Parellada M, Moreno C, Moreno M, Espliego A, de Portugal E, Arango C. Placebo effect in child and adolescent psychiatric trials. Eur Neuropsychopharmacol 2012;22:787-99.

31. Altunç U, Pittler MH, Ernst E. Homeopathy for childhood and adolescence ailments: systematic review of randomized clinical trials. Mayo Clin Proc 2007;82:69-75.

32. Ernst E, Barnes J. Meta-analysis of homoeopathy trials. Lancet 1998;351:366; author reply 367-8.

33. Vlieg-Boerstra BJ, van der Heide S, Bijleveld CM, Kukler J, Duiverman EJ, Dubois AE. Placebo reactions in double-blind, placebo-controlled food challenges in children. Allergy 2007;62:905-12.

34. Evers S, Marziniak M, Frese A, Gralow I. Placebo efficacy in childhood and adolescence migraine: an analysis of double-blind and placebo-controlled studies. Cephalalgia 2009;29:436-44.

35. Eccles R. Mechanisms of the placebo effect of sweet cough syrups. Respir Physiol Neurobiol 2006;152:340-8.

36. Klosterhalfen S, Enck P. The placebo effect. In: Haselgrove M, Hogarth L, eds. Clinical Applications of Learning Theory. London: Psychology Press, 2012:135-52.

37. Colloca L, Benedetti F. Placebo analgesia induced by social observational learning. Pain 2009;144:28-34.

38. Furmark T, Appel L, Henningsson S, et al. A link between serotonin-related gene polymorphisms, amygdala activity, and placebo-induced relief from social anxiety. J Neurosci 2008;28:13066-74.

39. Leuchter AF, McCracken JT, Hunter AM, Cook IA, Alpert JE. Monoamine oxidase a and catechol-o-methyltransferase functional polymorphisms and the placebo response in major depressive disorder. J Clin Psychopharmacol 2009;29:372-7.

40. Lindstedt F, Berrebi J, Greayer E, et al. Conditioned pain modulation is associated with common polymorphisms in the serotonin transporter gene. PLoS ONE 2011;6:e18252.

41. Stockhorst U, Spennes-Saleh S, Körholz D, et al. Anticipatory symptoms and anticipatory immune responses in pediatric cancer patients receiving chemotherapy: features of a classically conditioned response? Brain Behav Immun 2000;14:198-218.

42. Stockhorst U. Supportive therapeutic techniques in high-emetogenic cancer chemotherapy. Klin Padiatr 2008;220:330-2.

43. Sandler A. Placebo effects in developmental disabilities: implications for research and practice. Ment Retard Dev Disabil Res Rev 2005;11:164-70.

44. Rothner AD, Wasiewski W, Winner P, Lewis D, Stankowski J. Zolmitriptan oral tablet in migraine treatment: high placebo responses in adolescents. Headache 2006;46:101-9.

45. Vitiello B, Davis M, Greenhill LL, Pine DS. Blindness of clinical evaluators, parents, and children in a placebo-controlled trial of fluvoxamine. J Child Adolesc Psychopharmacol 2006;16:219-25. 
46. Rutherford BR, Sneed JR, Tandler JM, Rindskopf D, Peterson BS, Roose SP. Deconstructing pediatric depression trials: an analysis of the effects of expectancy and therapeutic contact. J Am Acad Child Adolesc Psychiatry 2011;50:782-95.

47. Diener HC, Dowson AJ, Ferrari M, Nappi G, Tfelt-Hansen P. Unbalanced randomization influences placebo response: scientific versus ethical issues around the use of placebo in migraine trials. Cephalalgia 1999;19:699-700.

48. Suchman AL, Ader R. Classic conditioning and placebo effects in crossover studies. Clin Pharmacol Ther 1992;52:372-7.

49. Rutherford BR, Mori S, Sneed JR, Pimontel MA, Roose SP. Contribution of spontaneous improvement to placebo response in depression: a metaanalytic review. J Psychiatr Res 2012;46:697-702.

50. Kelley JM, Lembo AJ, Ablon JS, et al. Patient and practitioner influences on the placebo effect in irritable bowel syndrome. Psychosom Med 2009;71:789-97.

51. Rostami-Hodjegan A, Abdul-Manap R, Wright CE, Tucker GT, Morice $\mathrm{AH}$. The placebo response to citric acid-induced cough: pharmacodynamics and gender differences. Pulm Pharmacol Ther 2001;14:315-9.

52. Aslaksen PM, Bystad M, Vambheim SM, Flaten MA. Gender differences in placebo analgesia: event-related potentials and emotional modulation. Psychosom Med 2011;73:193-9.

53. Lewis DW, Kellstein D, Dahl G, et al. Children's ibuprofen suspension for the acute treatment of pediatric migraine. Headache 2002;42:780-6.

54. Raz A. Hypnobo: perspectives on hypnosis and placebo. Am J Clin Hypn 2007;50:29-36.

55. Geers AL, Wellman JA, Fowler SL, Helfer SG, France CR. Dispositional optimism predicts placebo analgesia. J Pain 2010;11:1165-71.

56. Reynaert C, Janne P, Vause M, Zdanowicz N, Lejeune D. Clinical trials of antidepressants: the hidden face: where locus of control appears to play a key role in depression outcome. Psychopharmacology (Berl) 1995;119:449-54.

57. Flaten MA, Aslaksen PM, Lyby PS, Bjørkedal E. The relation of emotions to placebo responses. Philos Trans R Soc Lond, B, Biol Sci 2011;366:1818-27.

58. O'Hea EL, Moon S, Grothe KB, et al. The interaction of locus of control, self-efficacy, and outcome expectancy in relation to HbAlc in medically underserved individuals with type 2 diabetes. J Behav Med 2009;32:10617.

59. den Boer JJ, Oostendorp RA, Beems T, Munneke M, Oerlemans M, Evers AW. A systematic review of bio-psychosocial risk factors for an unfavourable outcome after lumbar disc surgery. Eur Spine J 2006;15: 527-36.

60. Newcorn JH, Sutton VK, Zhang S, et al. Characteristics of placebo responders in pediatric clinical trials of attention-deficit/hyperactivity disorder. J Am Acad Child Adolesc Psychiatry 2009;48:1165-72.

61. Cohen D, Consoli A, Bodeau N, et al. Predictors of placebo response in randomized controlled trials of psychotropic drugs for children and adolescents with internalizing disorders. J Child Adolesc Psychopharmacol 2010;20:39-47.

62. Sanchez LE, Armenteros JL, Small AM, Campbell M, Adams PB. Placebo response in aggressive children with conduct disorder. Psychopharmacol Bull 1994;30:209-13.

63. Guite JW, Logan DE, McCue R, Sherry DD, Rose JB. Parental beliefs and worries regarding adolescent chronic pain. Clin J Pain 2009;25:223-32.

64. Evers AW, Lu Y, Duller P, van der Valk PG, Kraaimaat FW, van de Kerkhof PC. Common burden of chronic skin diseases? Contributors to psychological distress in adults with psoriasis and atopic dermatitis. $\mathrm{Br}$ J Dermatol 2005;152:1275-81.

65. Lewis DW, Winner P, Wasiewski W. The placebo responder rate in children and adolescents. Headache 2005;45:232-9.

66. Grelotti DJ, Kaptchuk TJ. Placebo by proxy. BMJ 2011;343:d4345.

67. Whalley B, Hyland ME. Placebo by proxy: the effect of parents' beliefs on therapy for children's temper tantrums. J Behav Med 2012; e-pub ahead of print 12 May 2012.

68. Mangione-Smith R, McGlynn EA, Elliott MN, Krogstad P, Brook RH. The relationship between perceived parental expectations and pediatrician antimicrobial prescribing behavior. Pediatrics 1999;103(4 Pt 1):711-8.

69. Rief W, Nestoriuc Y, Weiss S, Welzel E, Barsky AJ, Hofmann SG. Metaanalysis of the placebo response in antidepressant trials. J Affect Disord 2009;118:1-8

70. Enck P, Bingel U, Schedlowski M, Rief W. The placebo response in medicine: minimize, maximize or personalize? Nat Rev Drug Discov 2013;12:191-204.

71. Ader R, Mercurio MG, Walton J, et al. Conditioned pharmacotherapeutic effects: a preliminary study. Psychosom Med 2010;72:192-7.

72. Sandler AD, Glesne CE, Bodfish JW. Conditioned placebo dose reduction: a new treatment in attention-deficit hyperactivity disorder? J Dev Behav Pediatr 2010;31:369-75.

73. Colloca L, Miller FG. Harnessing the placebo effect: the need for translational research. Philos Trans R Soc Lond, B, Biol Sci 2011;366:1922-30.

74. van Laarhoven AI, Vogelaar ML, Wilder-Smith $\mathrm{OH}$, et al. Induction of nocebo and placebo effects on itch and pain by verbal suggestions. Pain 2011;152:1486-94.

75. Vase L, Robinson ME, Verne GN, Price DD. Increased placebo analgesia over time in irritable bowel syndrome (IBS) patients is associated with desire and expectation but not endogenous opioid mechanisms. Pain 2005;115:338-47.

76. Goodenough B, Kampel L, Champion GD, et al. An investigation of the placebo effect and age-related factors in the report of needle pain from venipuncture in children. Pain 1997;72:383-91.

77. Sandler A, Glesne C, Geller G. Children's and parents' perspectives on open-label use of placebos in the treatment of ADHD. Child Care Health Dev 2008;34:111-20.

78. Kaptchuk TJ, Friedlander E, Kelley JM, et al. Placebos without deception: a randomized controlled trial in irritable bowel syndrome. PLoS ONE 2010;5:e15591.

79. Enck P, Klosterhalfen S, Zipfel S. Novel study designs to investigate the placebo response. BMC Med Res Methodol 2011;11:90.

80. Enck P, Grundy D, Klosterhalfen S. A novel placebo-controlled clinical study design without ethical concerns - the free choice paradigm. Med Hypotheses 2012;79:880-2.

81. Klosterhalfen S, Kellermann S, Braun S, et al. Gender and the nocebo response following conditioning and expectancy. J Psychosom Res 2009;66:323-8.

82. Fineberg NA, Hawley CJ, Gale TM. Are placebo-controlled trials still important for obsessive compulsive disorder? Prog Neuropsychopharmacol Biol Psychiatry 2006;30:413-22.

83. Stein DJ, Baldwin DS, Dolberg OT, Despiegel N, Bandelow B. Which factors predict placebo response in anxiety disorders and major depression? An analysis of placebo-controlled studies of escitalopram. J Clin Psychiatry 2006;67:1741-6. 